\title{
DECLIVE DEMOGRÁFICO \\ Y CAMBIO ECONÓMICO EN LAS ÁREAS DE MONTAÑA ESPAÑOLAS, 1860-2000*
}

\author{
FERNANDO COLLANTES GUTIÉRREZ \\ Universidad de Zaragoza ${ }^{\mathrm{a}}$
}

\begin{abstract}
RESUMEN
Este trabajo analiza el declive demográfico experimentado por las 84 principales comarcas de montaña españolas, que representan más del 20 por cien del territorio nacional y que, en torno a 1860, concentraban el 15 por cien de la población del país. La despoblación de la montaña española fue más tardía que la de las montañas de los países europeos más desarrollados, si bien, una vez arrancada, fue muy intensa en perspectiva comparada. La despoblación se generalizó durante la segunda mitad del siglo XX como consecuencia de importantes carencias en la calidad de vida de las montañas, carencias que a su vez estaban vinculadas al escaso grado de diversificación de su economía y a las dificultades en-

\footnotetext{
* Premio Ramón Carande 2003. Este trabajo desarrolla los principales resultados de mi investigación doctoral, El declive demográfico y económico de las zonas de montaña en España: un análisis a largo plazo (1850-2000) (Universidad de Cantabria, 2002/03), dirigida por Rafael Domínguez, a quien dedico este premio. Me he beneficiado igualmente de los comentarios y sugerencias de Vicente Pérez Moreda, Carles Sudrià, Sebastián Coll, James Simpson, Vicente Pinilla, Marta Guijarro, María Hierro, Jon Mathieu, Javier Silvestre y los asistentes al curso Factores de crecimiento económico regional en España, siglos XIX y XX (Jaca, 2002) y a los seminarios de la Universitat de Barcelona (2002) y la Universidad de Zaragoza (2002), y los evaluadores anónimos. Agradezco también la ayuda financiera prestada por el Centro de Estudios sobre la Despoblación y Desarrollo de Áreas Rurales (CEDDAR).

a Dpto. Estructura e Historia Económica y Economía Pública, Facultad de Ciencias Económicas y Empresariales, Gran Vía 4, 50005 Zaragoza. collantf@unizar.es.
} 
contradas por la población a la hora de acceder a equipamientos y servicios básicos. La despoblación actuó además como mecanismo de selección económica, en la medida en que contribuyó a la desaparición de la economía campesina tradicional y a la emergencia «por defecto» de formas más diversificadas.

Palabras clave: despoblación rural, economía de montaña, niveles de vida rurales, cambio estructural, España

\begin{abstract}
This paper analyses the demographic decline experienced by Spain's 84 main mountainous districts, which cover more than 20 per cent of the national surface and had 15 per cent of the country's total population in 1860. In Spain, mountain depopulation took place later than in other, more advanced European countries. However, once it started, the process was very intense in comparative perspective. Depopulation became a general phenomenon during the second half of the twentieth century as a consequence of significant shortcomings in rural welfare these shortcomings were related in turn to low degrees of economic diversification and high levels of penalty on the access to basic equipment and services. Furthermore, depopulation acted as a mechanism for economic selection because it contributed to the disappearance of the traditional peasant economy and the «default» emergence of more diversified patterns.
\end{abstract}

Keywords: rural depopulation, mountain economy, rural living standards, structural change, Spain

JEL Classification: J21, N33, N34, N93, N94

\title{
1. INTRODUCCIÓN
}

En 1975, la Directiva 75/268 estableció las bases a partir de las cuales los distintos Estados miembros de la CEE podrían diseñar medidas de asistencia a sus zonas de montaña. Esto supuso el reconocimiento oficial de la importancia de los espacios montañosos dentro de una economía europea caracterizada en aquellos momentos por la culminación de cambios estructurales kuznetsianos, como el aumento de las tasas de urbanización o el trasvase de población desde el campo hacia la ciudad. En aquel nuevo escenario, las políticas de montaña de los Estados miembros, entre ellas la española (aprobada en 1982, cuatro años antes del ingreso en la Comunidad), se fijaron como objetivo frenar el declive demográfico que la mayor parte de estos espacios venía sufriendo y ejercer una acción compensadora sobre las 
externalidades negativas que, tanto en el plano social como en el plano ecológico, se atribuían a la evolución reciente de las economías de montaña.

Pero la importancia estratégica de las montañas dentro del continente europeo no era nueva. La fragmentada configuración geomorfológica del continente ha sido aludida como uno de los factores explicativos de los cambios institucionales que hicieron posible «el milagro europeo» en la Edad Moderna ${ }^{1}$. Más adelante, durante los siglos XVIII y XIX, los resultados de las economías europeas dependieron en buena medida de factores que, como el desempeño del sector agrario, la disponibilidad de recursos energéticos (básicamente carbón y electricidad) o la formación de un mercado nacional unificado, venían condicionados por la geografía y, en muchos de los países, por las características y localización de los macizos montañosos².

Pese a situarse fuera de la principal cordillera europea, los Alpes, España es uno de los países más montañosos del continente: de acuerdo con la delimitación oficial, casi el 40 por cien del territorio nacional es montañoso. Este registro está lejos del 60-70 por cien en que se mueven pequeños países alpinos como Suiza o Austria, pero es superior al de los principales países del «centro» europeo, Francia (21 por cien) incluida ${ }^{3}$. En consecuencia, el estudio de la evolución demográfica y económica de la montaña española no sólo resulta de interés en el contexto de las actuales políticas europeas de desarrollo rural, sino que también es susceptible de revelar algunas claves de análisis en torno al proceso de crecimiento con cambios estructurales experimentado por la economía española a lo largo del último siglo y medio.

El presente trabajo se centra en los principales espacios montañosos del país, divididos en cuatro grandes áreas geográficas: Norte, Pirineo, Interior y Sur (figura 1). Se trata de 84 comarcas caracterizadas por altitudes y/o pendientes muy notables, que abarcan el 22 por cien del territorio nacional y que, en torno a 1860, llegaron a concentrar al 15 por cien de la población española ${ }^{4}$. El periodo escogi-

\footnotetext{
${ }^{1}$ Jones (1990, pp. 151-152, 272-273).

${ }^{2}$ Para el caso español, véanse por ejemplo Sudrià y Bartolomé (2003, pp. 78-79), Pascual y Sudrià (2002, pp. 239-241), Domínguez (2002, p. 97) y Llopis (2002, pp. 128).

${ }^{3}$ Bazin y Barjolle (1990, p. 4), Herbin y Remmer (1984, p. 27).

${ }^{4}$ Éstas son las comarcas, definidas conforme al Ministerio de Agricultura (1978):

Norte: Interior (Pontevedra); Barco de Valdeorras, Verín (Orense); Sanabria (Zamora); Montaña (Lugo); La Cabrera, Bierzo, Montaña de Luna, Montaña de Riaño (León); Vegadeo, Luarca, Cangas de Narcea, Grado, Belmonte de Miranda, Mieres, Llanes, Cangas de Onís (Asturias); Guardo, Cervera, Aguilar (Palencia); Liébana, Tudanca-Cabuérniga, Pas-Iguña, Asón, Reinosa (Cantabria); Merindades (Burgos); Cantábrica, Estribaciones Gorbea, Montaña Alavesa (Álava).

Pirineo: Cantábrica-Baja Montaña, Alpina (Navarra); Jacetania, Sobrarbe, Ribagorza (Huesca); Valle de Arán, Pallars-Ribagorza, Alto Urgel, Conca, Solsonés (Lérida); Bergadá (Barcelona); Cerdaña, Ripollés (Gerona).

Interior: Demanda (Burgos); Sierra Rioja Alta, Sierra Rioja Media, Sierra Rioja Baja (La Rioja); Pinares, Tierras Altas-Valle del Tera, Arcos de Jalón (Soria); Jaraiz de la Vera (Cáceres); Barco de Ávila-Piedrahita, Gredos, Valle Bajo Alberche, Valle del Tiétar (Ávila); Segovia (Segovia), Lozoya
} 


\section{FIGURA 1}

\section{LAS COMARCAS DE MONTAÑA DE NORTE, PIRINEO, INTERIOR Y SUR}

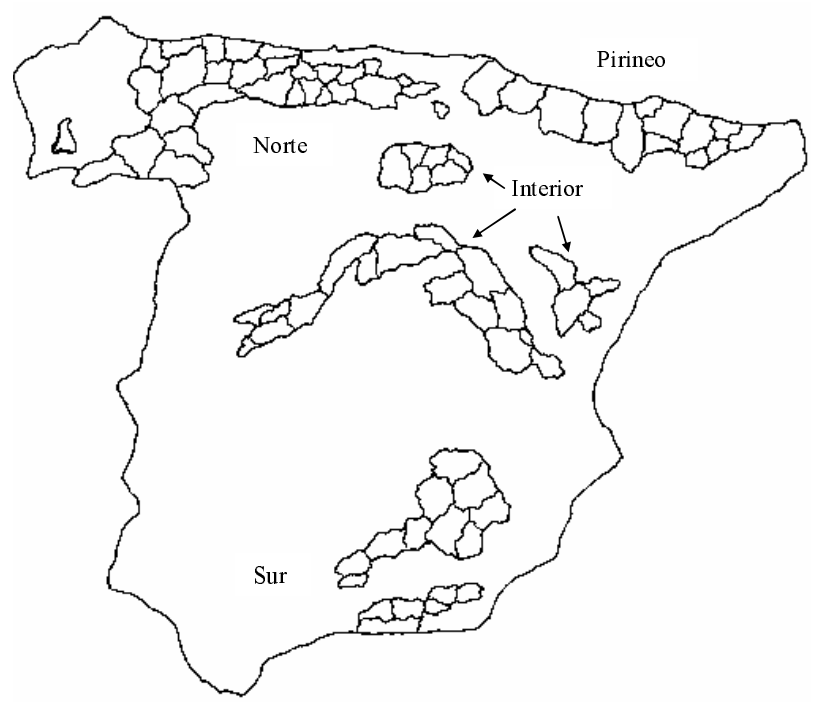

do, desde 1860 hasta la actualidad, permitirá circunscribir el análisis a los procesos desencadenados en el marco del «crecimiento moderno» de la economía española. Ha sido en este periodo cuando han tenido lugar las mutaciones más profundas en las estructuras económicas y demográficas de la montaña.

Tras esta introducción, el segundo apartado del artículo ilustra el declive demográfico experimentado por la montaña española a lo largo del último siglo y medio, y lo compara con lo ocurrido en las zonas de montaña de otros países europeos. Con objeto de situar dicho declive en su contexto económico, el apartado siguiente proporciona una perspectiva de largo plazo del cambio en la economía de montaña, con particular atención a los aspectos sectoriales del mismo. Esta perspectiva estructural es enlazada, en el cuarto apartado, con algunas aproximaciones físicas a la calidad de vida de los habitantes de la montaña y a la evo-

Somosierra (Madrid); Sierra, Molina de Aragón, Alcarria Baja (Guadalajara); Serranía Alta, Serranía Baja (Cuenca); Rincón de Ademuz, Alto Turia (Valencia); Serranía de Albarracín, Serranía de Montalbán, Maestrazgo (Teruel); Alto Maestrazgo, Peñagolosa (Castellón).

Sur: Sierra Alcaraz, Sierra Segura (Albacete); Noroeste (Murcia); Sierra de Segura, Mágina, Sierra de Cazorla, Sierra Sur (Jaén); Montefrío, Huéscar, La Costa, Las Alpujarras, Valle de Lecrín (Granada); Los Vélez, Río Nacimiento, Campo Tabernas, Alto Andarax (Almería). 
lución histórica de la misma en términos relativos. Finalmente, en el quinto apartado se integran las variables precedentes en una discusión acerca de los determinantes de la dinámica poblacional y los efectos de esta última sobre el cambio económico.

\section{EL DECLIVE DEMOGRÁFICO: COMPARACIONES EUROPEAS}

Si la población de las comarcas seleccionadas representaba el 15 por cien de la población española en 1860, hoy en día este porcentaje ha caído por debajo del 4 por cien. Esto no quiere decir, sin embargo, que la montaña española venga perdiendo población desde mediados del siglo XIX. Entre 1860 y 1950, las comarcas de montaña registraron un leve crecimiento demográfico (cuadro 1). Es cierto que, para 1950, la población de estas comarcas representaba ya menos del 10 por cien de la población española y que esto, junto con la existencia de un saldo migratorio persistentemente negativo, puede entenderse como señal de un declive demográfico de tipo relativo. Pero los movimientos migratorios aún no absorbían más que una porción del crecimiento vegetativo, y la composición de la población por edades o sexo no presentaba aún desequilibrios agudos derivados del carácter selectivo de la migración.

Durante el tercer cuarto del siglo XX, sin embargo, los movimientos migratorios triplicaron su intensidad y comenzó la despoblación. Alcanzada esta extraordinaria magnitud, la migración desequilibró las estructuras demográficas tradicionales y elevó los índices de envejecimiento. Ello desembocó en un descenso imparable de las tasas de crecimiento vegetativo, que finalmente terminaron por hacerse negativas en la década de $1980^{5}$. De este modo, la despoblación se volvió un proceso dependiente de la trayectoria. Y, aunque a partir de la década de 1970 la intensidad migratoria disminuyó y la despoblación tendió a desacelerarse, el balance de la segunda mitad del siglo XX ha sido rotundo: de los casi 2,7 millones de habitantes de 1950 se ha pasado a poco más de millón y medio en la actualidad.

Las trayectorias demográficas comparadas de Norte, Pirineo, Interior y Sur han guardado algunos paralelismos indudables, en particular la aceleración sin precedentes de las salidas migratorias en el subperiodo 1950-70, que supuso la ruptura definitiva hacia la despoblación y sus consecuencias demográficas. Sin embargo, tanto la trayectoria previa a 1950 como la intensidad de la despoblación registrada a partir de entonces diferencian de manera notable a unas y otras zonas de montaña. La crisis demográfica más intensa se ha registrado en la montaña Interior. Ya antes

${ }^{5} \mathrm{El}$ proceso fue común al resto del medio rural español, pero afectó con mayor intensidad a las áreas de montaña, como se desprende de la comparación entre los datos del cuadro 1 y los de García Sanz (1996, pp. 109-110, 113). Sobre la importancia analítica de la década de 1950, véase Reher (2003, pp. 21-24). 


\section{CUADRO 1}

\section{EL DECLIVE DEMOGRÁFICO}

\begin{tabular}{|lccccc|}
\hline \multicolumn{7}{r}{$\begin{array}{c}\text { Total } \\
\text { montaña }\end{array}$} & Norte & Pirineo & Interior & Sur \\
\hline \multicolumn{7}{l}{ Variación demográfica (tasa acumulativa anual) } \\
$1860-1900$ & 0,0 & 0,1 & $-0,5$ & 0,1 & 0,2 \\
$1900-1950$ & 0,2 & 0,2 & 0,1 & 0,0 & 0,5 \\
$1950-1970$ & $-1,2$ & $-0,8$ & $-0,7$ & $-2,0$ & $-1,4$ \\
$1970-2000$ & $-1,0$ & $-1,1$ & $-0,3$ & $-1,2$ & $-1,0$ \\
\multicolumn{7}{l}{ Tasa migratoria } & tantos por mil) & & & & \\
$1860-1900$ & $-5,5$ & $-5,3$ & $-10,0$ & $-3,7$ & $-4,8$ \\
$1900-1950$ & $-7,2$ & $-6,7$ & $-5,2$ & $-9,2$ & $-7,2$ \\
$1950-1970$ & $-22,3$ & $-16,8$ & $-14,2$ & $-29,8$ & $-30,3$ \\
$1970-2000$ & $-13,1$ & $-13,2$ & $-4,2$ & $-14,0$ & $-17,6$ \\
Índice de envejecimiento (Población mayor de 65 años / Población menor de 16 años) \\
1887 & 0,14 & 0,16 & 0,14 & 0,13 & 0,11 \\
1981 & 0,73 & 0,74 & 0,69 & 1,03 & 0,55 \\
2001 & 1,94 & 2,44 & 1,70 & 2,23 & 1,30 \\
Tasa de crecimiento vegetativo (tantos por mil) & & & \\
$1886-1892$ & 4,4 & 4,0 & 5,5 & 4,5 & 4,6 \\
$1981-1991$ & $-1,2$ & $-2,5$ & $-1,0$ & $-2,6$ & 2,3 \\
$1991-2000$ & $-4,7$ & $-6,8$ & $-3,4$ & $-5,8$ & $-0,6$ \\
\hline
\end{tabular}

Fuente: Censo(s) de Población de 1860, 1887, 1900, 1950, 1970, 1981, 1991 y 2001, www.ine.es, Collantes (2001a, p. 110), Movimiento Natural de la Población de 1982-2001.

de 1950, en algunas de sus comarcas (particularmente en el Sistema Ibérico) se inició un proceso de despoblación que no se ha detenido hasta nuestros días; en conjunto, la población de la montaña Interior se mantuvo entre 1860 y 1950 prácticamente estacionaria. Durante la segunda mitad del siglo XX, estos indicios de debilidad demográfica se verían plenamente confirmados por la más extrema demostración del carácter retroalimentado de la despoblación. El Pirineo fue, en cambio, la zona con menores pérdidas demográficas entre 1950 y 2000, a pesar de que también mostró previamente síntomas de debilidad al sufrir descensos poblacionales destacados durante la segunda mitad del siglo XIX. Sin embargo, su trayectoria demográfica se estabilizó durante la primera mitad del siglo XX y, como se ha señalado, ha sido con posterioridad la menos decadente dentro de la montaña española.

Las zonas de montaña del Norte y el Sur no mostraron, por su parte, grandes síntomas de debilidad en el periodo previo a 1950. La montaña Sur, de hecho, registró un destacado crecimiento poblacional, tendencia que se vio súbitamente truncada a partir de la década de 1950. La acumulación previa de una voluminosa reserva demográfica explica en parte que las dependencias secuenciales de la 
despoblación (crecimiento vegetativo negativo, envejecimiento) no se hallen, pese a todo, en una fase tan avanzada como en el resto de la montaña española. Finalmente, la evolución demográfica de la montaña Norte no difiere mucho de la evolución general ya descrita: leve crecimiento poblacional hasta 1950 y aceleración de las salidas migratorias a partir de entonces, si bien la despoblación no alcanzó los ritmos del Interior o el Sur.

¿Cómo encajan estas experiencias dentro de las pautas europeas? Los dos rasgos más sobresalientes de la despoblación de la montaña española son la tardanza de su arranque y la intensidad de la misma una vez iniciado el proceso (cuadro 2). En la montaña europea, la despoblación no ha sido, por lo general, un fenómeno correspondiente a la segunda mitad del siglo XX, como en España. Desde el segundo tercio del siglo XIX, la industrialización de la economía europea provocó pérdidas demográficas en numerosos espacios de montaña, particularmente en los países del centro: tal fue el caso de las Tierras Altas escocesas y de toda la montaña francesa (Macizo Central, Pirineo y los macizos orientales, con los Alpes a la cabeza) ${ }^{6}$. La pauta seguida por la montaña española guarda más parecidos con el caso italiano: tomada en su conjunto, la montaña italiana tampoco comenzó a despoblarse hasta después de la Segunda Guerra Mundial, pero resulta significativo que, durante el periodo previo, los Alpes occidentales, geográficamente próximos a los principales núcleos industriales de un país con agudas disparidades regionales, sí perdieran población (como el Pirineo en España). En suma, la montaña española participó de un patrón de despoblación «retardado» en relación con los países del centro y similar al de los países mediterráneos de la periferia europea, como cabría esperar de sus diferentes ritmos de crecimiento económico y cambio estructural durante el periodo previo a la Segunda Guerra Mundial.

Pero, una vez arrancada, la despoblación de la montaña española ha destacado por su extraordinaria intensidad, incluso en comparación con otros países de la periferia europea. Ni en Italia ni en Portugal alcanzó la despoblación de las áreas montañosas un ritmo superior al 1 por cien acumulativo anual durante la segunda mitad del siglo XX (como sí lo hizo en España). Tampoco alcanzaron nunca tales extremos las pérdidas de las montañas de los países del centro, ya fuera después de la Segunda Guerra Mundial o en las primeras etapas de su proceso de despoblación. De hecho, en los Alpes franceses comenzaron a registrarse, tras la Segunda Guerra Mundial, casos de recuperación demográfica que en la montaña española sólo han comenzado a aparecer con cierta generalidad en la década de 1990. Este nuevo retardo también ha contribuido a que la despoblación de la

${ }^{6}$ El caso de la montaña suiza es excepcional en la medida en que el propio modelo suizo de crecimiento económico moderno fue también excepcional en el contexto europeo, caracterizándose por la dispersión espacial de la industria y unas tasas de urbanización muy bajas en relación a su nivel de renta per cápita (Bergier, 1988, p. 210; Fritzsche, 1996, p. 137; Macura, 1981, pp. 91-97; Lawton y Lee, 1989, pp. 3-4). 


\section{CUADRO 2}

\section{LA EVOLUCIÓN DEMOGRÁFICA DE OTRAS ZONAS DE MONTAÑA EUROPEAS}

\begin{tabular}{|c|c|c|c|c|}
\hline & \multicolumn{2}{|c|}{ c. $1850-c .1950$} & \multicolumn{2}{|c|}{ Después de 1950} \\
\hline & Tasa & Periodo & Tasa & Periodo \\
\hline \multicolumn{5}{|l|}{ Gran Bretaña } \\
\hline Tierras Altas escocesas & $-0,3$ & 1851-1951 & 0,2 & $1951-80$ \\
\hline Francia & & & $-0,6$ & $1950-88$ \\
\hline Alpes del Norte & $-0,3$ & 1831-1911 & 0,3 & $1946-82$ \\
\hline Alpes del Sur & $-0,5$ & c. $1850-1946$ & 0,6 & 1946-82 \\
\hline Macizo Central & $-0,4$ & 1831-1911 & $-0,1$ & $1982-90$ \\
\hline Pirineo & $-0,3$ & 1831-1911 & 0,0 & $1982-90$ \\
\hline Italia & 0,3 & 1881-1956 & $-0,7 / 0,1$ & $1961-71$ / 1981-90 \\
\hline Alpes occidentales & $-0,3$ & 1881-1936 & & \\
\hline Alpes centrales y orientales & 0,2 & 1881-1936 & & \\
\hline Alpes (total) & 0,0 & 1881-1936 & 0,1 & 1961-71 \\
\hline Apeninos & 0,3 & 1881-1936 & $-1,2$ & $1961-71$ \\
\hline Suiza & 0,7 & $1850-1950$ & 0,9 & $1950-91$ \\
\hline Portugal & & & $-0,6$ & $1960-81$ \\
\hline
\end{tabular}

Fuente: Devine (1979, p. 355), Bryden (1981, p. 483), Désert (1992a, pp. 68-69; 1992b, p. 371), Thorez y Reparaz (1987, p. 100), Desbordes y Laborie (1991, pp. 8-9), Meyzenq (1984, p. 41), Estienne (1989, p. 398), Rieutort (1997, p. 69), Barberis (1992, p. 70), Mazzoleni y Negri (1981, p. 27), Cappuccini (1958, p. 440), Giusti (1943, pp. 304-305), Office Féderal de la Statistique (2002), Castro y Belo (1992, p. 120).

montaña española durante la segunda mitad del siglo XX resulte particularmente intensa en comparación con el patrón centroeuropeo.

\section{LA ECONOMÍA DE MONTAÑA EN EL LARGO PLAZO}

Desde mediados del siglo XIX, la economía española se vio inmersa en una dinámica de crecimiento con cambios estructurales llamada a operar vastas transformaciones en los más diversos órdenes de la sociedad, pero esta dinámica se abrió paso con significativas disparidades espaciales: así, a la altura de 1960, el 
porcentaje de ocupados agrarios estaba ya por debajo del 20 por cien en regiones como Cataluña o el País Vasco, pero se mantenía por encima del 60 por cien en Castilla-La Mancha, Extremadura o Galicia ${ }^{7}$. A escala comarcal, los contrastes podían ser aún más acusados, y precisamente las zonas de montaña proporcionan una de las mejores ilustraciones, ya que, aún en 1960, más del 75 por cien de su población activa permanecía empleada en el sector primario (cuadro 3). En contraste con la importante diversificación ocupacional que venía tomando cuerpo en los espacios más dinámicos del país, las economías de montaña fueron, hasta bien entrado el siglo XX, economías campesinas en las que la institución familiar desempeñaba un papel central de cara a la organización de la producción y la satisfacción de las necesidades ${ }^{8}$.

\section{CUADRO 3}

PORCENTAJE DE POBLACIÓN OCUPADA EN EL SECTOR PRIMARIO

\begin{tabular}{|ccccccc|}
\hline & Norte & Pirineo & Interior & Sur & $\begin{array}{c}\text { Total } \\
\text { montaña }\end{array}$ & $\begin{array}{c}\text { España no } \\
\text { montañosa }\end{array}$ \\
\hline 1887 & 89 & 77 & 83 & 83 & 85 & 67 \\
1960 & 78 & 65 & 85 & 81 & 78 & 36 \\
1981 & 42 & 21 & 41 & 55 & 41 & 14 \\
2001 & 15 & 9 & 15 & 25 & 16 & 6 \\
\hline
\end{tabular}

Fuente: Censo(s) de Población de 1887, 1960, 1981 y 2001, Censo Agrario de 1962 y CPDES (1963).

Estas economías campesinas de montaña tenían dos características que, aun estando en sintonía con los postulados de la obra clásica de Alexander Chayanov, no siempre han sido suficientemente subrayadas ${ }^{9}$. La primera de ellas era su destacado grado de apertura, como consecuencia de la activa participación de las familias campesinas en diversos mercados de productos y factores. Un corolario de ello es que la reproducción de las economías tradicionales de montaña estuvo vinculada a la reproducción de un sistema económico de rango superior con el que compartía

\footnotetext{
${ }^{7}$ Datos tomados de Domínguez (2002, p. 370).

${ }^{8}$ El contraste también se daba con respecto a otras áreas de montaña europeas. En torno a 1963, sólo el 40 por cien del empleo de las montañas francesa, italiana, suiza, austriaca y alemana correspondía al sector primario (Feldmann, 1963, p. 41); en las Tierras Altas escocesas, la proporción era inferior al 25 por cien (Bryden, 1981, p. 484).

${ }^{9}$ Véase Chayanov (1985, pp. 73, 117-20, 265).
} 
una serie de condicionantes tecnológicos e institucionales. En segundo lugar, las economías campesinas de montaña no eran exclusivamente agrarias: en el marco de estrategias diseñadas a escala familiar, diferentes miembros de las comunidades de montaña dedicaban habitualmente una porción de su esfuerzo laboral a actividades como la manufactura doméstica, el comercio a pequeña escala o la prestación de servicios de arriería y carretería, y también participaban de manera selectiva y estacional en ciertos mercados de trabajo (tanto rurales como urbanos) ${ }^{10}$.

Si estas actividades complementarias ya contribuían a dotar al modelo económico de la montaña del carácter abierto anteriormente aludido, también las propias explotaciones agropecuarias se encontraban alejadas del estereotipo autárquico. Sin perjuicio de que una parte de la producción agraria campesina se destinara a mercados locales (o, directamente, al autoconsumo familiar), las economías de montaña tendieron a forjar una suerte de «base exportadora agraria» que las conectaba a mercados más amplios. La industrialización del país, al venir acompañada de un incremento de la demanda urbana de ciertos productos agrarios y un descenso en los costes de transporte, reforzó los incentivos para la especialización campesina. En un contexto tecnológico de carácter orgánico, ello acentuó el peso de la dotación geográfica en la orientación productiva de las economías de montaña ${ }^{11}$. Así, la gradación norte-sur del índice de humedad terminó correspondiéndose con los diferentes pesos relativos de ganadería y agricultura dentro de las explotaciones agrarias (cuadro 4). Los campesinos de la montaña Norte aprovecharon su elevado índice de humedad (y sus buenas comunicaciones) para consolidar la pauta de especialización bovina que se había gestado durante la parte final del Antiguo Régimen. Una dotación climatológica igualmente favorable permitió del mismo modo la paulatina reconversión y diversificación de la ganadería pirenaica tras la crisis de la trashumancia ovina que había vertebrado la economía local antes de la industrialización. Los campesinos de la montaña Sur, en cambio, se orientaron cada vez en mayor medida hacia las producciones agrícolas, en consonancia con las restricciones que su dotación climatológica imponía sobre un crecimiento basado en la ganadería y con sus ventajas para el cultivo del olivar, el viñedo o, bajo determinadas condiciones, el propio cereal. La montaña Interior, por contra, aparece como un caso intermedio, con dificultades tanto para reconvertir su ganadería tras el declive de la tras-

\footnotetext{
${ }^{10}$ Collantes (2001b) desarrolla estas premisas en una revisión bibliográfica. Sobre estas características en otras economías de montaña europeas, véanse Smith (2001, pp. 49-50), Gray (1955, p. 368), Devine (1979, pp. 344-348, 356-358) y Bryden (1981, p. 478) para Escocia, Collomp (2000, p. 125) para Francia, Dadà (2000, p. 153), Perini (1958, p. 333), Vincent (1980, p. 261) y Crivelli (1994, pp. 95, 98n., 104) para Italia, McNeill (1992, pp. 103, 352) y Ortega (2003, pp. $20-$ 22) para toda la montaña mediterránea, Gross (1982, p. 253) para Austria, y Dobrowolski (1979, p. 267) para Polonia; véase también Dunaway (1996, pp. 360-361) para los Apalaches estadounidenses.

${ }^{11}$ Mathieu (2000, pp. 125, 140-141) subraya para los Alpes la influencia creciente de la geografía sobre los sistemas agrarios de montaña a lo largo del proceso de desarrollo económico.

${ }^{12}$ Las transformaciones de la ganadería y la agricultura de montaña se analizan de manera detallada en Collantes (2003a; 2004a).
} 
humancia como para seguir la senda agrícola de las sierras meridionales ${ }^{12}$.

A pesar de que las economías de montaña no perdieron su carácter campesino hasta bien entrado el siglo XX, ya desde mediados del siglo XIX fueron acumulándose en algunas comarcas elementos de diversificación sectorial y social. La industrialización moderna dio al traste con las manufacturas tradicionales dispersas por los pueblos de montaña, pero también creó nuevas oportunidades. Inicialmente, estas oportunidades se manifestaron en el plano minero-energético y en algunas ramas industriales; más adelante, y en particular durante la segunda mitad del siglo XX, el turismo se convertiría en sector motriz para varias áreas montañosas. La considerable magnitud de las inversiones requeridas provocó que muchas de estas nuevas oportunidades fueran aprovechadas por empresas ajenas a la comunidad campesina y a la propia montaña. Por esta vía, la dotación geográfica se volvió de nuevo un elemento crucial, en este caso a la hora de encauzar los capitales en busca de oportunidades de inversión hacia unas u otras regiones de montaña.

\section{CUADRO 4}

\section{LA ORIENTACIÓN PRODUCTIVA DE LAS ECONOMÍAS DE MONTAÑA}

\begin{tabular}{|c|c|c|c|c|c|c|}
\hline & Norte & Pirineo & Interior & Sur & $\begin{array}{c}\text { Total } \\
\text { montaña }\end{array}$ & $\begin{array}{l}\text { España no } \\
\text { montañosa }\end{array}$ \\
\hline \multicolumn{7}{|c|}{ Trilogía mediterránea (porcentaje sobre superficie agraria total) } \\
\hline 1888/9 & 13,9 & 10,6 & 23,1 & 36,1 & 20,0 & 44,5 \\
\hline 1999 & 3,3 & 5,5 & 12,3 & 27,5 & 11,0 & 37,2 \\
\hline \multicolumn{7}{|c|}{ Densidad ganadera (unidades ganaderas por $\mathrm{km}^{2}$ ) } \\
\hline 1865 & 24,8 & 15,7 & 15,1 & 9,5 & 17,3 & 15,6 \\
\hline $1917(*)$ & 20,4 & 13,1 & 12,2 & 8,4 & 14,3 & 13,0 \\
\hline 1999 & 23,1 & 24,0 & 15,5 & 9,1 & 18,3 & 32,9 \\
\hline \multicolumn{7}{|c|}{ Producción de carbón (miles de TEC por 100 km²) } \\
\hline 1900 & 3,0 & 0,3 & - & - & 1,0 & 0,4 \\
\hline 1950 & 17,6 & 1,1 & 0,4 & - & 5,9 & 1,3 \\
\hline 1988 & 25,3 & 0,9 & 1,2 & - & 8,1 & 3,4 \\
\hline \multicolumn{7}{|c|}{ Coeficientes de intensidad industrial (España=100) } \\
\hline 1951 & 19 & 74 & 16 & 4 & 21 & 108 \\
\hline 1989 & 35 & 93 & 13 & 8 & 34 & 103 \\
\hline \multicolumn{7}{|c|}{ Coeficientes de intensidad turística (España=100) } \\
\hline 1963 & 6 & 95 & 21 & 20 & 23 & 107 \\
\hline 1999 & 51 & 154 & 65 & 44 & 68 & 101 \\
\hline
\end{tabular}

(*): El dato está sesgado a la baja (Zapata, 1986, p. 602)

Fuente: Collantes (2003a, p. 145; 2003b, pp. 70-71, 78; 2004a, p. 84), Anuario(s) Banesto del mercado español de 1965 y 1966, Anuario Económico de España 2001 de La Caixa. 
En concreto, la disponibilidad de recursos naturales estratégicos y la proximidad física a los principales focos de la industrialización española condicionaron la capacidad de diversificación de las economías rurales. La explotación carbonífera transformó precozmente la vida económica de las comarcas asturianas y leonesas afectadas, pero ésta no era en absoluto una senda evolutiva generalizable a otras áreas. Del mismo modo, el notable ascenso de la función turístico-residencial en el Pirineo durante las décadas finales del siglo XX se ha basado, entre otros aspectos, en unas condiciones de altitud, pendiente e innivación que resultaban mucho más favorables que las de las otras cordilleras ${ }^{13}$. Finalmente, la diversificación por medio de procesos de difusión geográfica de la actividad industrial podía resultar factible en la parte oriental de la montaña Norte o en algunas comarcas navarras y catalanas del Pirineo, pero difícilmente podía darse en una montaña Sur enclavada en regiones atrasadas y con escasa capacidad propagadora ${ }^{14}$. Por todo ello, la mayor parte de las comarcas montañosas se encontraban escasamente diversificadas a la altura de 1950, cuando comenzó a generalizarse la despoblación. Desde entonces, el cambio estructural ha sido espectacular: el sector primario ya ocupaba a menos de la mitad de la población activa en 1981, y hoy en día más del 80 por cien de esta última se encuentra empleada en los sectores secundario y terciario. La conexión temporal entre declive demográfico y cambio económico invita a profundizar en los vínculos existentes entre ambos, discusión para la cual un análisis previo de los niveles relativos de bienestar resulta insoslayable.

\section{VIVIR EN LA MONTAÑA: EXPLORANDO LA «PENALIZACIÓN RURAL»}

A mediados del siglo XX, después de un siglo de industrialización en España, las economías de montaña se encontraban claramente rezagadas, en términos de cambio estructural, en la composición sectorial del empleo. ¿Se correspondía esto con una brecha importante en términos de bienestar? La respuesta no puede ser terminante. A falta de indicadores comparativos suficientemente generales, resulta plausible suponer (como se ha hecho en ocasiones análogas) que el escaso grado de diversificación ocupacional iba unido a niveles de renta inferiores a la media nacional ${ }^{15}$. Sin embargo, una definición más amplia de la calidad de vida, incorporando aspectos educativos y sanitarios, ofrece un balance más pondera-

${ }^{13}$ Lo cual está en sintonía con lo ocurrido en otras partes de Europa (Rieutort, 1997, pp. 74-75; Thorez y Reparaz, 1987, p. 105).

${ }^{14}$ Collantes (2003b) analiza esta desigual implantación de la minería y la industria moderna en las economías de montaña contemporáneas.

${ }^{15}$ En la línea de, por ejemplo, Williamson (1965, p. 32). Además, y como se desarrolla en el siguiente apartado, en torno a 1960/70 (primera fecha para la que disponemos de información estadística suficientemente general) la conexión entre diversificación ocupacional y nivel de renta resultaba clara. 


\section{CUADRO 5}

\section{LA CALIDAD DE VIDA EN LAS ECONOMÍAS DE MONTAÑA}

\begin{tabular}{|c|c|c|c|c|c|c|}
\hline & Norte & Pirineo & Interior & Sur & $\begin{array}{c}\text { Total } \\
\text { montaña }\end{array}$ & $\begin{array}{l}\text { España no } \\
\text { montañosa }\end{array}$ \\
\hline \multicolumn{7}{|c|}{ Tasa bruta de mortalidad } \\
\hline $1886 / 92$ & 27,0 & 27,8 & 35,4 & 34,2 & 30,6 & 31,6 \\
\hline \multicolumn{7}{|c|}{ Tasa bruta de alfabetización } \\
\hline 1860 & 28 & 21 & 28 & 13 & 24 & 24 \\
\hline 1910 & 50 & 46 & 42 & 19 & 41 & 41 \\
\hline 1963 & 74 & 74 & 73 & 68 & 73 & 75 \\
\hline \multicolumn{7}{|c|}{ Consumo de carne (kg. per cápita) } \\
\hline c. 1900 & 17,3 & 14,9 & 17,6 & 7,6 & 15,1 & n.d. \\
\hline \multicolumn{7}{|c|}{ Familias que no consumen habitualmente carne o pescado (\%) } \\
\hline 1963 & 44 & 33 & 60 & 73 & 53 & n.d. \\
\hline \multicolumn{7}{|c|}{ Densidad ferroviaria (metros de vía férrea por $\mathrm{km}^{2}$ ) } \\
\hline 1880 & 9,2 & 2,3 & 3,0 & - & 4,3 & 17,8 \\
\hline 1942 & 26,3 & 15,7 & 10,1 & 4,3 & 15,2 & 40,7 \\
\hline 1994 & 30,5 & 11,9 & 7,3 & 4,3 & 14,9 & 30,2 \\
\hline \multicolumn{7}{|c|}{ Densidad viaria (metros de carretera por $\mathrm{km}^{2}$ ) } \\
\hline 1896 & 28,9 & 14,3 & 20,3 & 18,2 & 21,5 & 35,1 \\
\hline 1957 & 63,1 & 70,5 & 43,4 & 47,8 & 55,4 & 137,2 \\
\hline 2002 & 84,5 & 83,9 & 57,1 & 42,1 & 68,0 & 185,7 \\
\hline \multicolumn{7}{|c|}{ Edificios residenciales con abastecimiento de agua corriente (\%) } \\
\hline 1963 & 35 & 68 & 26 & 32 & 36 & 47 \\
\hline \multicolumn{7}{|c|}{ Edificios residenciales con evacuación de aguas residuales (\%) } \\
\hline 1963 & 33 & 53 & 25 & 27 & 32 & 38 \\
\hline \multicolumn{7}{|c|}{ Número de viviendas por edificio residencial } \\
\hline 1970 & 1,21 & 1,59 & 1,10 & 1,07 & 1,18 & 1,92 \\
\hline 2001 & 1,45 & 2,11 & 1,28 & 1,31 & 1,43 & 2,52 \\
\hline \multicolumn{7}{|c|}{ Índice de dotación educativa $($ España $=100)$} \\
\hline 1903 & 158 & 113 & 128 & 54 & 119 & 98 \\
\hline 1997 & 36 & 47 & 40 & 48 & 39 & 119 \\
\hline \multicolumn{7}{|c|}{ Teléfonos por 1.000 habitantes } \\
\hline 1963 & 22 & 54 & 30 & 15 & 26 & 95 \\
\hline 1991 & 254 & 413 & 430 & 209 & 297 & 404 \\
\hline \multicolumn{7}{|c|}{ Índice de dotación comercial (España = 100) } \\
\hline 1963 & 46 & 73 & 33 & 39 & 43 & 114 \\
\hline 2000 & 38 & 60 & 39 & 37 & 40 & 117 \\
\hline \multicolumn{7}{|c|}{ Índice de dotación de servicios financieros $($ España $=100)$} \\
\hline 1963 & 58 & 74 & 34 & 35 & 48 & 113 \\
\hline 2000 & 33 & 42 & 38 & 28 & 33 & 120 \\
\hline \multicolumn{7}{|c|}{ Renta familiar disponible per cápita $($ España $=100)$} \\
\hline 1970 & 69 & 87 & 74 & 52 & 71 & 107 \\
\hline 1999 & 91 & 115 & 93 & 73 & 91 & 100 \\
\hline
\end{tabular}

Fuente: Movimiento Natural de la Población Española de 1886-92, Collantes (2004b, p. 142; 2005), Censo(s) ganadero(s) de 1891 y 1917, GEHR (1991), Comín y otros (1998), Uriol (1990-2), Mapa de España de Carreteras Firestone (1957), Mapa Oficial de Carreteras (2001), Censo de la Vivienda de 1970, Censo de Edificios de 1970, Censo de Población de 2001, Censo escolar de 1903, Anuario Social de España 2000 de La Caixa, Anuario(s) Banesto del Mercado Español de 1965, 1966, 1992 y 1993. 
do (cuadro 5) ${ }^{16}$. En la economía campesina con mayor calidad de vida, la de la montaña Norte, la tasa de mortalidad era inferior a la media nacional y el proceso de alfabetización se encontraba más avanzado que en el resto del país; a ello habría que añadir apreciables niveles de consumo cárnico y patrones distributivos no excesivamente desequilibrados ${ }^{17}$.

Desde luego, la imagen no sería extensible a todas las zonas. Los campesinos de la montaña Sur experimentaban una masiva privación de sus capacidades básicas (utilizando la terminología de Amartya Sen): las luchas contra la mortalidad y el analfabetismo seguían siendo asignaturas pendientes a finales del siglo XIX, y además los estándares alimenticios resultaban en muchos casos precarios (incluso en una fecha tan tardía como 1963, la mayor parte de familias no consumía habitualmente ni carne ni pescado $)^{18}$. En realidad, las economías campesinas de montaña reproducían las correspondientes disparidades regionales en cuanto a calidad de vida, con la mortalidad intensificando su acción fuera de las húmedas regiones septentrionales y la pobreza y el analfabetismo como rasgos característicos de los territorios meridionales. Fue sobre todo a lo largo del siglo XX, y de la mano de la consolidación y culminación de la industrialización, cuando se generó una apreciable «penalización rural» en el bienestar, en la medida en que las ciudades concentraron cada vez en mayor medida no sólo los progresos económicos (en particular, los sectores motrices del crecimiento), sino también avances sociales más amplios, como el acceso a diversos equipamientos y servicios que rápidamente pasaron a formar parte del estándar mínimo de decoro al que alude Adam Smith ${ }^{19}$.

Así, durante la segunda mitad del siglo XX, mientras la despoblación se generalizaba y la estructura ocupacional se desagrarizaba y convergía así con la media nacional, la calidad de vida de las poblaciones de montaña se deterioró de manera

\footnotetext{
16 Sobre la necesidad de incorporar estas variables durante las etapas iniciales de la industrialización, véase Domínguez y Guijarro (2000, p. 114).

${ }^{17}$ Las ventajas sanitarias de las montañas han sido comúnmente subrayadas; véanse Braudel (1987, pp. 64-65) y Viazzo (1994, pp. 100-101, 113-115; 2000, p. 35). La tasa bruta de mortalidad es un indicador tosco de la calidad de vida, ya que no permite incorporar las diferencias intercomarcales en la estructura de la población por edades. Sin embargo, y de acuerdo con el Censo de 1887, estas diferencias no eran muy grandes y, además, las distorsiones por ellas provocadas sesgan la evidencia en contra de la argumentación presentada (en tanto en cuanto la montaña Sur es precisamente la región con una estructura menos envejecida). La imagen proporcionada por este tosco indicador concuerda a grandes rasgos, además, con la ofrecida por aproximaciones más finas como la de Reher (1998, pp. 94-97).

${ }^{18}$ Sen (2000, p. 114). Estas deficiencias eran comunes al resto de la montaña mediterránea europea (McNeill, 1992, pp. 127-128). En general, la comparación de los niveles de vida de las economías campesinas de montaña españolas con las del resto de Europa arroja, como cabía esperar, resultados poco favorables: véanse los datos de Furet y Ozouf $(1977$, p. 8) y Cipolla (1983, pp. 20, 89-90) para la alfabetización, Viazzo (2000, p. 35) para la mortalidad y Désert y Specklin (1992, p. 100) para el consumo de carne.

${ }^{19}$ Cfr. Sen (2000, p. 98).
} 
muy clara en términos relativos. La introducción de sistemas de abastecimiento de agua corriente y evacuación de aguas residuales, por ejemplo, se realizó en las viviendas de montaña con retraso respecto al resto del país, y lo mismo ocurrió con el servicio telefónico. Estas brechas básicas se encuentran hoy en día prácticamente cerradas (a diferencia de lo que acontecía en el momento álgido de la despoblación), pero se mantienen algunas de las disfunciones asociadas a la vida en espacios de baja densidad demográfica, como la dificultad de acceso a los servicios comerciales y financieros. Del mismo modo, a lo largo del siglo XX se ha producido un espectacular deterioro relativo de la dotación educativa en la montaña. A todo ello se une su tradicional infradotación en materia de vías férreas y carreteras, que fue ganando en gravedad conforme progresaba la motorización de la sociedad española. Finalmente, la renta per cápita de la montaña representaba en 1970 tan sólo el 71 por cien de la media nacional, y parece plausible estimar un nivel bastante inferior en torno a 1950, antes de que la emigración masiva tendiera a estimular un peculiar proceso de convergencia "por defecto», es decir, liderado más por los decrementos poblacionales que por los aumentos de la renta ${ }^{20}$.

El análisis comparado revela, de todos modos, importantes contrastes regionales. Todas las zonas de montaña estuvieron (y están) expuestas a la penalización rural, pero no en igual grado. Dentro de unos límites, las comarcas podían mitigar la magnitud de su penalización rural en la medida en que fueran capaces de poner en marcha procesos genuinos de diversificación económica que difundieran algunos de los componentes (pecuniarios y no pecuniarios) del bienestar urbano. De hecho, las economías más diversificadas y con menor penalización rural tendieron además a concentrar a la mayor parte de su población en cabeceras comarcales, y no tanto ya en pequeños núcleos dispersos (como queda reflejado de facto en su mayor número de viviendas por edificio residencial) ${ }^{21}$. El mejor ejemplo viene dado por el Pirineo, que ha marchado a la cabeza de la muestra en prácticamente todos los indicadores considerados. La aparición y consolidación de actividades manufactureras y turísticas hizo posible que, a la altura de 1970, la renta per cápita estuviera próxima ya al 90 por cien de la media nacional; hoy en día, después de tres décadas de expansión turístico-residencial, esta renta es incluso un 15 por cien superior a dicha media. Paralelamente, los habitantes del Pirineo, cada vez más agrupados en núcleos de población de tamaño medio, disfrutaban de un mejor acceso que los de otras montañas a los equipamientos y servicios básicos.

${ }^{20}$ Collantes (2004b) se centra en estos patrones de convergencia económica «por defecto».

${ }^{21}$ Esta última variable tiende a uno en condiciones de ruralidad extrema y puede actuar como aproximación al grado de urbanización sin presentar los problemas que la variedad de estructuras de poblamiento de nuestro medio rural y la utilización del municipio como unidad base suscitan de cara a la interpretación comparativa de las tasas de urbanización convencionales; véase García Sanz (1996, p. 346). 
En la montaña Sur, en cambio, las insuficiencias en el bienestar de la economía campesina persistieron, en ausencia de elementos de diversificación que alteraran sustancialmente el panorama, y se amplificaron conforme el estándar urbano fue progresando. En el tercer cuarto del siglo XX, la renta per cápita estaría, en la estimación más optimista, en torno a la mitad de la media nacional, y el porcentaje de hogares equipados con teléfono, agua corriente o alcantarillado era bajo incluso en comparación con la media de la montaña. En la montaña Interior, donde las economías campesinas habían proporcionado niveles de vida más aceptables, el nivel de equipamiento de los hogares no era mejor. Además, las bajas densidades de población (en 1950, antes de la emigración masiva, apenas había diecisiete habitantes por $\mathrm{km}^{2}$ y el registro era muy inferior a ése en varias comarcas del Sistema Ibérico), unidas a la extrema dispersión del poblamiento, la ausencia de pequeños núcleos semi-urbanos y la persistente infradotación de vías férreas y carreteras, dificultaron (y dificultan) el acceso a servicios clave.

Finalmente, la montaña Norte no pudo mantener el puesto relativo que ostentaba a finales del siglo XIX, pero tampoco experimentó la penalización rural en un grado tan extremo como las sierras interiores y meridionales. Así, por ejemplo, el carácter estratégico de su posición geográfica de cara a la comunicación del interior peninsular con la cornisa cantábrica proporcionó desde mediados del siglo XIX una dotación de infraestructuras muy aceptable para los estándares de montaña, si bien es cierto que, como ocurría simultáneamente con el proceso de diversificación económica, un buen número de comarcas quedó al margen. En cualquier caso, tanto en la montaña Norte como en el resto de áreas consideradas, parece claro que la brecha de calidad de vida con respecto al medio urbano afectaba a numerosos elementos del bienestar cotidiano y se encontraba ligada a la dinámica general del cambio económico. En mi opinión, éste es el terreno en el que debemos reintegrar a la despoblación en el análisis.

\section{LA CRISIS DEMOGRÁFICA COMO MECANISMO DE SELECCIÓN ECONÓ- MICA}

Como se señaló en el segundo apartado, la despoblación de la montaña española fue, en términos generales, un fenómeno correspondiente a la segunda mitad del siglo XX. Durante este periodo, la mayor parte de comarcas montañosas perdió población, inicialmente como consecuencia de intensas salidas migratorias y más adelante también como consecuencia de una variación natural negativa, en buena medida relacionada con los efectos de las propias salidas migratorias sobre la estructura por edades. La elevada correlación entre ambas vertientes del cambio demográfico permite un análisis unitario del mismo, sin perjuicio de las aportaciones que futuras investigaciones más específicas pue- 
dan realizar ${ }^{22}$. ¿Cuáles fueron los determinantes de este cambio demográfico? Desde el punto de vista teórico, algunas variables aparecen como candidatas claras: así, por ejemplo, los diferenciales de bienestar (y, particularmente, de renta per cápita) resultan una pieza importante en la mayor parte de enfoques, incluyendo el neoclásico, el marxista o el institucionalista-evolucionista ${ }^{23}$. Desde una óptica más aplicada, el desarrollo de la historiografía (nacional e internacional) ha subrayado también la influencia de la estructura del empleo, la dotación de servicios o las características del poblamiento sobre la trayectoria demográfica de las áreas rurales durante el siglo $\mathrm{XX}^{24}$. Otras hipótesis más tradicionales, como las relacionadas con las características de los sistemas de herencia campesina o los efectos de expulsión generados por las reformas agrarias liberales, se encuentran por el contrario en una posición débil en este momento ${ }^{25}$.

De los resultados del cuadro 6 se desprende que, durante la segunda mitad del siglo XX, la crisis demográfica de la montaña española vino impulsada por dinámicas compatibles con los principales planteamientos teóricos y aplicados al respecto. La despoblación afectó con mayor dureza a aquellas comarcas con una estructura económica poco diversificada (con una elevada proporción de ocupados agrarios), bajos niveles de renta per cápita, tipos de poblamiento con características acentuadamente rurales (aspecto aproximado a través del número medio de viviendas por edificio residencial) y una marcada penalización rural en el bienestar. En realidad, estas últimas variables también se encontraban correlacionadas entre sí, configurando de este modo un vector más amplio de transformación

${ }^{22}$ En realidad, las tasas migratorias guardan correlaciones superiores a 0,85 con respecto a la variación demográfica total para todas las décadas del periodo 1950-2000. No en vano, la correlación entre la tasa migratoria aproximada para el periodo 1950-81 y el índice de envejecimiento en 1981 asciende a -0,57 y, a su vez, este índice de envejecimiento está muy relacionado en sentido inverso con la variación natural de la población a partir de entonces (los coeficientes de correlación son de -0,83 tanto para la década de 1980 como para la de 1990).

${ }^{23}$ Collantes (2001b) valora la aplicabilidad de éstos y otros enfoques teóricos al estudio de este caso concreto.

${ }^{24} \mathrm{La}$ importancia de la estructura sectorial del empleo ha sido señalada para el caso español por García Sanz (1996, p. 72) y, para otras zonas de montaña europeas, por Diry (1995, pp. 2324), Dorfmann (1983, p. 22), Estienne (1989, pp. 395-398, 401-405), Mazzoleni y Negri (1981, pp. 29-30), Negri (1993, pp. 65-67), Freschi (1993, p. 34), Billet y Rougier (1984, pp. 12, 16 17) y Herbin y Remmer (1984, pp. 24-25). Los aspectos relacionados con la penalización rural se encuentran más ausentes; véase en cierto modo Gumuchian y otros (1980, pp. 312, 316) para el caso francés. Sobre la relevancia analítica de las características del poblamiento, Sancho (1997).

${ }^{25}$ La hipótesis sobre los sistemas de herencia campesina soporta mal el análisis comparativo, como muestra Comas (1995, pp. 149-150). Algo parecido ocurre con los argumentos basados en los efectos de expulsión de la privatización de comunales o la construcción de embalses, que guardan escasa sintonía con la caracterización actual de la privatización como un proceso ampliamente influido por las inercias locales (GEHR, 1994) y con las trayectorias demográficas comparadas de las distintas regiones de montaña (Collantes, 2003b, p. 76), respectivamente. 
socioeconómica. La ausencia de cambio estructural en la composición sectorial del empleo, por ejemplo, iba asociada a bajos niveles de renta (confirmando así una conexión habitualmente aludida en la literatura aplicada) y patrones de poblamiento acusadamente rurales ${ }^{26}$.

\section{CUADRO 6}

MATRIZ DE CORRELACIONES A NIVEL COMARCAL (N = 84)

\begin{tabular}{|lrrrrr|}
\hline & $(1)$ & $(2)$ & (3) & (4) & (5) \\
\hline (1) Variación demográfica (1950-2000) & 1,00 & & & & \\
(2) Porcentaje de ocupados agrarios (1960) & $-0,63$ & 1,00 & & & \\
(3) Viviendas por edificio (1970) & 0,67 & $-0,75$ & 1,00 & & \\
(4) Penalización rural (1960) & $-0,58$ & 0,55 & $-0,63$ & 1,00 & \\
(5) Renta per cápita (1970) & 0,54 & $-0,64$ & 0,66 & $-0,77$ & 1,00 \\
\hline
\end{tabular}

Fuente: Véanse cuadros 1, 3 y 5. Para cuantificar la penalización rural se ha elaborado un índice sintético que incorpora las siguientes variables mediante el procedimiento expuesto en Domínguez y Guijarro (2000, pp. 115-116): densidad viaria, porcentaje de edificios con agua corriente y evacuación de aguas residuales, dotación educativa, teléfonos por 1.000 habitantes, dotaciones de servicios comerciales y financieros. Por limitaciones en las fuentes, el número de viviendas por edificio y la renta per cápita no han podido introducirse para fechas previas a 1970, pero ello no parece generar grandes distorsiones en el primer caso (parece plausible admitir que la pauta de variabilidad intercomarcal sería en 1950 aproximadamente similar a la de 1970) y sesga los resultados en mi contra en el segundo (al utilizar la renta de 1970, las correlaciones son menores de lo que habrían sido de haber dispuesto de la variable para 1950, ya que se ven contaminadas por dos décadas de convergencia «por defecto»).

De este modo, a partir de la década de 1950 cristalizaron definitivamente dinámicas tendentes a la desaparición de las economías rurales tradicionales. En los casos de mayor éxito, como los de la comarca Cantábrica alavesa, el Valle de Arán (Lérida) o la Cerdaña (Gerona), una economía rural diversificada era capaz de evitar la despoblación gracias a su capacidad para transformarse en un sentido similar al del conjunto del país, con creación de empleo en los sectores secundario y terciario y escasas brechas relativas en el nivel de bienestar (logro en parte conectado, a su vez, a las características cada vez más urbanas de la estructura del poblamiento).

\footnotetext{
${ }^{26}$ La conexión entre diversificación ocupacional y elevados niveles de renta ya había sido señalada por García Sanz (1996, pp. 251-252, 278-279, 289) para el conjunto de las áreas rurales españolas.
} 
En el resto de casos, que constituían una amplia mayoría, la incapacidad de la economía rural para transformarse en una dirección tal se tradujo en el desencadenamiento de una crisis demográfica cuyas secuelas son aún hoy perceptibles. Pero la vida rural tradicional estaba llamada a su fin de todos modos: la crisis demográfica activó cambios estructurales «por defecto» en la composición sectorial del empleo, los niveles de renta y la organización del trabajo. Para el conjunto de la montaña española, el crecimiento del porcentaje de empleos no agrarios (del 22 al 84 por cien entre 1960 y 2001) fue más rápido que el crecimiento del empleo no agrario en términos absolutos, dado que el decremento de la población activa agraria generado por la despoblación contribuyó a acelerar el proceso de diversificación ${ }^{27}$. Entre 1960 y 1991, de hecho, más de la mitad de la velocidad de diversificación alcanzada por las economías de montaña se debió a este tipo de efecto (y la proporción de diversificación «genuina» sólo superó el 75 por cien en el caso pirenaico, no en vano la economía que en mayor medida había desarrollado sus sectores industrial y turístico ${ }^{28}$. De manera similar, la mayor parte de comarcas experimentaron convergencia «por defecto» en rentas per cápita, hasta el punto de que la brecha con respecto a la media nacional, que llegó a ser del 30 por cien en 1970 (y, presumiblemente, aún mayor en torno a 1950, antes de que comenzara la despoblación generalizada), no supera hoy el 10 por cien. Finalmente, el mercado desplazó a la familia como mecanismo principal para la asignación de los recursos laborales: más de la mitad de la población ocupada era ya población asalariada en 1981, y hoy se alcanzan registros superiores al 70 por cien.

${ }^{27}$ Llamando $d$ al porcentaje de ocupados en los sectores secundario y terciario, $D$ al número de ocupados en dichos sectores y $P A$ a la población activa, se tiene que:

$$
\begin{gathered}
d=D / P A \\
r(d)=r(D)-r(P A)
\end{gathered}
$$

donde $r$ son tasas de crecimiento acumulativo anual. En un escenario kuznetsiano de cambio estructural «genuino», $r(d)>0$ porque $r(D)>0, r(P A)>0$ y $r(D)>r(P A)$. Esto es: hay una tendencia hacia la diversificación porque el aumento de los empleos fuera de la agricultura se produce más deprisa que el aumento de la población activa. En cambio, en un escenario de despoblación, $r(P A)<0$, por lo que la diversificación se produce como resultado de la suma de dos fuerzas: el aumento de los empleos fuera de la agricultura y la disminución de la población activa. El protagonismo relativo de la senda de diversificación «genuina» $(g)$ puede medirse, en términos porcentuales, como la ratio entre el aumento de los empleos fuera de la agricultura y el aumento del porcentaje de ocupados fuera de la agricultura:

$$
g=[r(D) / r(d)] * 100
$$

siendo $(100-g)$ el protagonismo relativo de la senda de diversificación «por defecto».

${ }^{28}$ La evidencia de casos similares en otras partes de la montaña europea se encuentra por el momento poco desarrollada. Los casos del Apenino toscano-emiliano en la década de 1950 (Cocco, 1967, p. 7) y de la comarca suiza de Pays-d’Enhaut entre 1950 y 1980 (Sauvain, 1988, p. 206) se ajustaron al patrón descrito, si bien la proporción de diversificación «genuina» ascendió al 52 y el 62 por cien respectivamente; por el contrario, en las Tierras Altas escocesas entre 1961 y 1977, el cambio estructural no se produjo «por defecto» (Bryden, 1981, p. 484). 
En suma, el cambio demográfico funcionó como mecanismo de selección de formas económicas, impulsando el desmantelamiento de la vida rural tradicional en la mayor parte de la montaña española y refrendando el dinamismo de un pequeño grupo de comarcas capaces de ofrecer niveles satisfactorios de bienestar ${ }^{29}$. Pero, ¿por qué no se produjeron estas transformaciones con anterioridad a 1950, como en otros países europeos? La pertenencia del caso español a un patrón periférico de acontecimientos invita a considerar el menor grado de desarrollo económico alcanzado durante el siglo XIX y el primer tercio del XX. Éste se reflejó en un ritmo moderado de crecimiento de la demanda urbana del factor trabajo que resultó insuficiente para provocar la despoblación generalizada de las áreas de montaña. A ello cabe añadir que fue sobre todo durante la segunda mitad del siglo XX cuando se acentuó la penalización rural en el bienestar. Así, antes de 1950 la despoblación sólo afectó a un grupo limitado de comarcas de montaña, casi todas ellas pertenecientes al Pirineo o al Sistema Ibérico y caracterizadas por: (1) el hundimiento de sus bases exportadoras tradicionales, y (2) su proximidad geográfica a los principales destinos y/o sus elevados niveles educativos, factores ambos que favorecieron la transformación de la potencialidad migratoria en migración efectiva ${ }^{30}$. Para buena parte de la montaña española, sin embargo, el aprovechamiento de ventajas absolutas o comparativas en los sectores agrario y minero y los elevados costes informativos y pecuniarios del desplazamiento se combinaron durante este periodo con una expansión moderada de las oportunidades urbanas para aplazar el inicio de la despoblación ${ }^{31}$. La acelerada culminación de la industrialización española a partir de la década de 1950 alteraría hasta tal punto el entorno de las economías de montaña que éstas no podrían ya persistir en su forma tradicional: allí donde el cambio económico no avanzara de manera genuina, el declive demográfico se encargaría de activarlo por defecto.

\section{CONCLUSIONES}

El declive demográfico de la montaña española ha formado parte de los cambios estructurales asociados al crecimiento económico moderno. Así, en el contexto europeo, la montaña española participó de un patrón periférico-mediterráneo de despoblación tardía: las pérdidas poblacionales no se generalizaron hasta la segunda mitad del siglo XX, aproximadamente un siglo más tarde que en Gran

${ }^{29}$ La evolución económica como proceso de selección y extinción de formas o instituciones económicas, en Veblen (1998).

${ }^{30}$ Collantes (2005) se centra en estos aspectos educativos y analiza con mayor detalle su incidencia sobre las propensiones migratorias.

${ }^{31}$ Lo cual encaja con las propuestas realizadas por Prados de la Escosura (1988), Gallego (1993, pp. 253-254; 2001), Silvestre (2001) y Núñez (2001). 
Bretaña o Francia. Ahora bien, la extrema gravedad de la crisis demográfica registrada durante las últimas cinco décadas no encuentra referentes claros de comparación en otras partes de Europa, al menos de manera tan generalizada. Esta crisis se ha visto motivada por el desequilibrio de los niveles de bienestar entre las áreas urbanas y unas comarcas rurales con estructuras económicas poco diversificadas, bajos niveles de renta y acceso deficiente a numerosos equipamientos y servicios.

La diversidad de situaciones y trayectorias dentro de la propia montaña española ha sido, de todos modos, muy notable. Las comunidades campesinas de la montaña Norte aprovecharon sus condiciones ecológicas para desarrollar, sobre la base de pequeñas explotaciones muy intensivas en trabajo familiar, una especialización ganadera bovina que se consolidó en el marco del proceso de urbanización de la sociedad española. Paralelamente, la explotación de los yacimientos de carbón de algunas de sus comarcas generó numerosos puestos de trabajo. La solidez de estas bases exportadoras permitió a la montaña Norte experimentar un ligero crecimiento demográfico entre 1860 y 1950. Durante la segunda mitad del siglo XX, sin embargo, la expansión de la demanda laboral urbana y la profundización de la penalización rural (en la que previamente había sido la economía campesina con mayor calidad de vida) provocaron la aceleración de las salidas migratorias. No se trató, de todos modos, de una despoblación muy intensa.

El Pirineo, en cambio, perdió población ya antes de 1950. En su caso, a la crisis de la ganadería ovina trashumante se unió la intensa atracción ejercida por los cercanos núcleos industriales vascos y, sobre todo, catalanes. Sin embargo, al mismo tiempo que la economía pirenaica estaba muy expuesta a estos efectos de polarización, también pudo beneficiarse en gran medida de efectos de difusión. Desde mediados del siglo XIX se consolidaron algunos centros industriales de tamaño medio (tanto de bienes de consumo como de bienes de equipo), y en las últimas décadas se ha registrado un irresistible ascenso de la función turísticoresidencial. Además, a lo largo del siglo XX, este proceso de diversificación ocupacional vino acompañado de niveles de renta cada vez más elevados y de un acceso relativamente satisfactorio (al menos en relación con el resto de la montaña española) a equipamientos y servicios constitutivos del estándar urbano de bienestar. Entre 1950 y 2000, el Pirineo no logró evitar la despoblación, pero sí mitigó la magnitud de las pérdidas y, en estos momentos, es el principal foco de recuperación demográfica (en la década de 1990, siete de sus trece comarcas ganaron población), un fenómeno común en otras partes de la montaña europea pero aún incipiente en la montaña española.

En el otro extremo, la montaña Interior registró el declive más acusado, con espectaculares índices de envejecimiento y pérdida poblacional. Ya antes de 1950, las crisis de la trashumancia y de la manufactura preindustrial golpearon duramente a un buen número de sus comarcas. Distintas partes del Sistema Ibérico comenzaron a despoblarse en el siglo XIX, y prácticamente toda la cordillera per- 
dió población a lo largo del siglo XX. Esto no sólo se debió a la debilidad de la base exportadora agraria de las economías campesinas (ante los obstáculos ecológicos para encarar una reconversión ganadera más profunda o para reorientar las explotaciones hacia la especialización agrícola), sino también a factores como las altas tasas de alfabetización de algunas comarcas o la proximidad geográfica de los principales focos receptores de migración interior en España. Durante la segunda mitad del siglo XX, la emigración se aceleró y la despoblación se extendió también al Sistema Central. Su intensidad no sólo fue consecuencia del escaso grado de diversificación alcanzado (en ausencia, por ejemplo, de las ventajas pirenaicas para el crecimiento turístico), sino también de la considerable penalización que el hábitat marcadamente rural imponía sobre los niveles de bienestar.

Finalmente, los habitantes de la montaña Sur han sido, a lo largo de todo el periodo considerado, los que han disfrutado de una peor calidad de vida. A finales del siglo XIX, la elevada mortalidad, el analfabetismo y los reducidos niveles de consumo alimenticio señalaban a la montaña Sur como la menos próspera entre las economías campesinas de montaña. Ello no impidió, sin embargo, un fuerte crecimiento demográfico entre 1860 y 1950. ¿Por qué? En primer lugar, porque la base exportadora agraria (en este caso, agrícola) no sólo no se derrumbó, sino que se expandió notablemente. En segundo lugar, el alejamiento de las regiones industriales del país y el analfabetismo masivo impidieron la consecución de tasas migratorias más altas. La despoblación sólo se produjo a partir de 1950. Dado que, a lo largo de todo el periodo considerado, ni la dotación natural ni la pertenencia geográfica a la España del atraso favorecieron la formación de una estructura económica medianamente diversificada, y dado que la pobreza relativa se manifestaba tanto en los niveles de renta como en el acceso a equipamientos y servicios, no resulta sorprendente que las pérdidas poblacionales estuvieran entre las más altas de la montaña española.

Tanto en la montaña Sur como en el resto de áreas afectadas por la despoblación, la crisis demográfica tuvo como consecuencia la activación de una peculiar senda de cambio estructural «por defecto». Como resultado de ello, incluso las economías de montaña menos dinámicas en perspectiva histórica se habían convertido, en el tramo final del siglo XX, en economías relativamente diversificadas. No todos los componentes de la política rural y de montaña desarrollada en las últimas décadas han estado en sintonía con ello, pero este tema excede ya los límites del presente trabajo.

\section{BIBLIOGRAFÍA}

AlBera, D. y CoRTI, P. (coords.) (2000): La montagna mediterranea: una fabbrica d'uomini? Mobilità e migrazioni in una prospettiva comparata (secoli XV-XX). Cuneo: Gribaudo. 
BARBERIs, C. (1992): «La montagne ou les montagnes italiennes, identités et civilisation». Revue de Géographie Alpine 4, pp. 65-76.

Bazin, G. y Barjolle, D. (1990): «La politique de montagne en Suisse. Quelques enseignements pour la France». Économie Rurale 197, pp. 3-8.

Bergier, J. F. (1988): «El modelo suizo», en D. Landes y otros, La revolución industrial. Barcelona: Crítica, pp. 205-221.

Billet, J. y Rougier, H. (1984): «L’évolution récente de la population des Alpes suisses». Revue de Géographie Alpine 72 (1), pp. 9-20.

Braudel, F. (1987) [1966]: El Mediterráneo y el mundo mediterráneo en la época de Felipe II. México: FCE.

BRYDEN, J. (1981): «Appraising a regional development programme - The case of the Scottish Highlands and Islands». European Review of Agricultural Economics 8 (4), pp. 475-497.

Cappuccinı, G. (1958): «L'evoluzione dell'economia montana in Italia». Rivista Italiana di Economia, Demografia e Statistica 12 (1-2), pp. 431-447.

Castro, J. y Belo, M. (1992): «Quelle perspective pour les agricultures dans les zones de montagne du Portugal?». Revue de Géographie Alpine 4, pp. 117-127.

Chayanov, A. V. (1985): La organización de la unidad económica campesina. Buenos Aires: Nueva Visión, 1924.

Cipolla, C. M. (1983) [1969]: Educación y desarrollo en Occidente. Barcelona: Ariel.

Cocco, E. di (1967): «Equilibri territoriali e settoriali nella storia recente dell’Appennino tosco-emiliano». Rivista di Politica Agraria 14 (2), pp. 7-13.

Collantes, F. (2001a): «La migración en la montaña española, 1860-1991: construcción de una serie histórica». Revista de Demografía Histórica 19 (1), pp. 105-138.

- (2001b): «El declive demográfico de la montaña española, 1860-1991: revisión crítica de propuestas teóricas». Historia Agraria 24, pp. 203-225.

- (2003a): «La ganadería de montaña en España, 1865-2000: Historia de una ventaja comparativa anulada». Historia Agraria 31, pp. 141-167.

- (2003b): «Energía, industria y medio rural: el caso de las zonas de montaña españolas (1850-2000)». Revista de Historia Industrial 23, pp. 65-93.

- (2004a): «La evolución de la actividad agrícola en las zonas de montaña españolas (18602000)». Revista de Estudios Agrosociales y Pesqueros 201, pp. 79-104.

- (2004b): «Convergencia económica ‘por defecto’ en el medio rural español: el caso de las zonas de montaña (1970-2000)». Revista Asturiana de Economía 29, pp. 135-155.

- (2005): «Las disparidades educativas en la España rural contemporánea, 1860-2000: un análisis comparado de las comarcas montañosas». Revista de Demografía Histórica 22 (2), pp. 15-52.

Collomp, A. (2000): «Migrazioni e sistema familiare in Provenza nei secoli XVIII e XIX», en D. Albera y P. Corti (coords.), pp. 121-130.

Comas, D. (1995): «Familia, sistema de herencia y estratificación social. Estrategias hereditarias y despoblación», en J. L. Acín y V. Pinilla (coords.), Pueblos abandonados. ¿Un mundo perdido? Zaragoza: Rolde, pp. 141-152.

Comín, F., Martín Aceña, P., Muñoz, M. y Vidal, J. (1998): 150 Años de Historia de los Ferrocarriles Españoles. Madrid: Fundación de los Ferrocarriles Españoles.

Comín, F., Hernández, M. y Llopis, E. (eds.) (2002): Historia económica de España. Siglos $X-X X$. Barcelona: Crítica. 
CPDES [Comisaría del Plan de Desarrollo Económico y Social] (1963): Factores humanos y sociales. Madrid: Imprenta Nacional del BOE.

CRIVELLI, R. (1994): «Rationalité et vie quotidienne en montagne: un regard historique». Revue de Géographie Alpine 3, pp. 95-106.

DADÀ, A. (2000): «Uomini e strade dell'emigrazione dall’Appennino toscano», en D. Albera y P. Corti (coords.), pp. 153-164.

Desbordes, F. y LaborIe, J. P. (1991): «L'évolution récente de la population dans les Pyrénées françaises». Revue Géographique des Pyrénées et du Sud-Ouest 62 (1), pp. 7-18.

DÉSERT, G. (1992a): «Vers le surpeuplement?», en E. Juillard (dir.), pp. 49-73.

— (1992b): «La grande dépression de l'agriculture», en E. Juillard (dir.), pp. 359-382.

- y SPECKLIN, R. (1992): «Victoire sur la disette», en E. Juillard (dir.), pp. 96-130.

Devine, T. M. (1979): «Temporary migration and the Scottish Highlands in the Nineteenth Century». Economic History Review 32 (3), pp. 344-359.

DiRY, J. P. (1995): «Moyennes montagnes d'Europe occidentale et dynamiques rurales». Revue de Géographie Alpine 3, pp. 15-26.

Dobrowolski, K. (1979): «La cultura campesina tradicional», en T. SHANIN (comp.), Campesinos y sociedades campesinas. México: FCE, pp. 249-267 (1958).

Domínguez, R. (2002): La riqueza de las regiones. Las desigualdades económicas regionales en España, 1700-2000. Madrid: Alianza.

- y Guijarro, M. (2000): «Evolución de las disparidades espaciales del bienestar en España, 1860-1930. El Índice Físico de Calidad de Vida». Revista de Historia Económica 18 (1), pp. 109-137.

Dorfmann, M. (1983): «Régions de la montagne: de la dépendance à l'auto-développement?». Revue de Géographie Alpine 71 (1), pp. 5-34.

Dunaway, W. A. (1996): «The Incorporation of Mountain Ecosystems into the Capitalist World-System». Review 19 (4), pp. 355-381.

Estienne, P. (1989): «Évolution de la population des montagnes françaises au $\mathrm{XX}^{\mathrm{e}}$ siècle». Revue de Géographie Alpine 77 (4), pp. 395-406.

Feldmann, C. (1963): «Salvare l'agricoltura di montagna». Rivista di Politica Agraria 10 (3), pp. 41-43.

Freschi, L. (1993): «La politique d'aménagement de la montagne au Tyrol du Sud (Italie): un modèle d'autodéveloppement». Revue de Géographie Alpine 2, pp. 31-49.

Fritzsche, B. (1996): «Switzerland», en M. Teich y R. Porter (eds.), The Industrial Revolution in national context: Europe and the USA. Cambridge: CUP, pp. 126-148.

Furet, F. y Ozouf, J. (1977): Lire et écrire. L'alphabétisation des français de Calvin a Jules Ferry. París: Editions de Minuit.

GALLEGo, D. (1993): «Pautas regionales de cambio técnico en el sector agrario español (19001930)». Cuadernos Aragoneses de Economía 3 (2), pp. 241-276.

- (2001): «Historia de un desarrollo pausado: integración mercantil y transformaciones productivas de la agricultura española (1800-1936)», en J. Pujol, M. González de Molina, L. Fernández Prieto, D. Gallego y R. Garrabou, El pozo de todos los males. Sobre el atraso en la agricultura española contemporánea. Barcelona: Crítica, pp. 147-214.

GARCía SANZ, B. (1996): La sociedad rural ante el siglo XXI. Madrid: MAPA.

GEHR (1991): Estadísticas históricas de la producción agraria española, 1859-1935. Madrid: MAPA. 
- (1994): «Más allá de la 'propiedad perfecta'. El proceso de privatización de los montes públicos españoles (1859-1926)». Historia Agraria 8, pp. 99-152.

Giusti, U. (1943): «Le dépeuplement des régions montagneuses en Italie». Bulletin Mensuel de Renseignements Économiques et Sociaux 34 (9), pp. 295-322.

Gray, M. (1955): «The Highland potato famine of the 1840's». Economic History Review 7 (3), pp. 357-368.

Gross, N. T. (1982): «La revolución industrial en la monarquía de los Habsburgo, 17501914», en C. M. Cipolla (ed.), Historia económica de Europa (4). El nacimiento de las sociedades industriales. Primera parte. Barcelona: Ariel, pp. 234-287 (1973).

Gumuchian, H., Meriaudeau, R. y Peltier, C. (1980): «L'isolement en montagne: éléments de réflexion». Revue de Géographie Alpine 68 (4), pp. 305-325.

Herbin, J. y Remmer, J. (1984): «L'évolution démographique des Alpes austro-allemandes». Revue de Géographie Alpine 72 (1), pp. 21-40.

JONES, E. L. (1990): El milagro europeo. Entorno, economía y geopolítica en la historia de Europa y Asia. Madrid: Alianza, 1987.

Juillard, E. (dir.) (1992): Histoire de la France rurale. 3. Apogée et crise de la civilisation paysanne de 1789 à 1914. Éditions du Seuil, 1976.

LAWTON, R. y LEE, R. (1989): «Introduction: the framework of comparative urban population studies in Western Europe, c. 1750-1920», en R. Lawton y R. Lee (eds.), Urban Population Development in Western Europe from the Late-Eighteenth to the EarlyTwentieth Century. Liverpool: Liverpool University Press, pp. 1-26.

LLopis, E. (2002): «Expansión, reformismo y obstáculos al crecimiento (1715-1789)», en F. Comín y otros (eds.), pp. 121-164.

McNeILl, J. R. (1992): The Mountains of the Mediterranean World: an environmental history. Cambridge: CUP.

Macura, M. (1981): «La población europea, 1920-1970», en C. M. Cipolla (ed.), Historia económica de Europa (5). El siglo XX. Primera parte. Barcelona: Ariel, pp. 13-103 (1974).

Mathieu, J. (2000): Storia delle Alpi 1500-1900. Ambiente, sviluppo e società. Casagrande: Bellinzona.

Mazzoleni, M. y Negri, G. G. (1981): «La situación de la montaña en Italia». Ciudad y Territorio 1, pp. 25-37.

Meyzenq, C. (1984): «La population des Alpes du Sud, Un nouvel équilibre?». Revue de Géographie Alpine 72 (1), pp. 41-53.

Ministerio De Agricultura (1978): Comarcalización agraria de España. Madrid.

Negri, G. G. (1993): «Les montagnes de Lombardie». Revue de Géographie Alpine 2, pp. 65-83.

NúÑEz, C. E. (2001): «Within the European Periphery: Education and Labor Mobility in Twentieth-Century Spain». VII Congreso de la Asociación de Historia Económica.

Office Féderal De La Statistique (2002): Eidgenössische Volkszählung 2000. Bevölkerungsentwicklung der Gemeinden 1850-2000. Berna.

OrtegA, A. (2003): «Introducción: a propósito de las montañas del Mediterráneo», en A. Ortega y J. Vignet (eds.), Las Montañas del Mediterráneo. Granada: Diputación Provincial, pp. 17-24.

PAscual, P. y SudRIÀ, C. (2002): «El difícil arranque de la industrialización (1840-1880)», en F. Comín y otros (eds.), pp. 203-241. 
PerinI, D. (1958): «I fattori economici e sociali della montagna alpina». Rivista di Economia Agraria 13 (2-3), pp. 324-335.

Prados De La Escosura, L. (1988): De imperio a nación. Crecimiento y atraso económico en España (1780-1930). Madrid: Alianza.

REHER, D. S. (1998): «Mortalidad rural y mortalidad urbana: un paseo por la transición demográfica en España», en F. Dopico y D. S. Reher, El declive de la mortalidad en España, 1860-1930. Zaragoza: ADEH, pp. 59-103.

- (2003): Perfiles demográficos de España, 1940-1960», en C. Barciela (ed.), Autarquía y mercado negro. El fracaso económico del primer franquismo, 1939-1959. Barcelona: Crítica, pp. 1-26.

Rieutort, L. (1997): «Les moyennes montagnes d'Europe occidentale: affaiblissement ou réadaptation des campagnes?». Norois 173, pp. 61-83.

SANcho, R. (1997): «Estructura demográfica y tipificación de los asentamientos y áreas rurales españolas», en C. Gómez Benito y J. J. González (eds.), Agricultura y sociedad en la España contemporánea. Madrid: CIS / MAPA, pp. 173-223.

SAuvain, P. (1988): «Desarrollo endógeno de las zonas de montaña. Pays-d’Enhaut (Suiza)». Agricultura y Sociedad 46, pp. 191-225.

Sen, A. (2000): Desarrollo y libertad. Barcelona: Planeta, 1999.

SiLVESTRE, J. (2001): «Viajes de corta distancia: una visión espacial de las migraciones interiores en España, 1877-1930». Revista de Historia Económica 19 (2), pp. 247-283.

Sмiтн, A. (2001): La riqueza de las naciones. Madrid: Alianza, 1776.

SudRIÀ, C. y BARTOLOMÉ, I. (2003): «La era del carbón», en J. Nadal (dir.), Atlas de la industrialización de España, 1750-2000. Barcelona: Fundación BBVA / Crítica, pp. 73-99.

Thorez, P. y Reparaz, A. de (1987): «La population et le peuplement dans le Caucase oriental et dans les Alpes du Sud. Formes traditionnelles, formes contemporaines, différenciations régionales». Méditerranée 61 (2-3), pp. 95-110.

Uriol, J. I. (1990-2): Historia de los caminos de España. Madrid: Colegio de Ingenieros de Caminos, Canales y Puertos.

Veblen, T. (1998): «Why is economics not an evolutionary science?». Cambridge Journal of Economics 22, pp. 403-414 (1898).

Viazzo, P. P. (1994): «Les modèles alpins de mortalité infantile». Annales de Démographie Historique, pp. 97-117.

— (2000): «Il modello alpino dieci anni dopo», en D. Albera y P. Corti (coords.), pp. 31-46.

VINCENT, J. A. (1980): «The political economy of Alpine development: tourism or agriculture in St. Maurice». Sociologia Ruralis 20 (4), pp. 250-271.

Williamson, J. G. (1965): «Regional inequality and the process of national development: A description of the patterns». Economic Development and Cultural Change 13 (4-2), pp. 3-45.

ZAPATA, S. (1986): La producción agraria de Extremadura y Andalucía occidental, 18751935. Madrid: Universidad Complutense. 